\title{
As manifestações institucionais e cotidianas do habitus*
}

\author{
Aaron V. Cicourel \\ Tradução de Sergio M iceli
}

Entendo o termo habituscomo umatentativa acadêmica radical com o obje tivo de conceituar processos pelosquais bebêse crianças adquirem capacidades- perceptivas, motoras, conceituais e verbais - que as identificam como integrantes competentes, "nativos" ou não, de um grupo ou de uma comunidade. Tal processo deslancha com o nascimento e, ressalto adiante, dura atéa morte. C aso se pretenda abordar com seriedade o tema do "inconsciente acadêmico", talvez se deva formular a seguintequestão: de que maneira a perspectiva acadêmica sobre o modo de socializar crianças em grupos ou em comunidades difere daquela mobilizada pelas pessoas comuns e sobretudo por aqueles que possuem uma descendência? A téque ponto essas perspectivas se mostram comparáveis ou, ao contrário, divergentes?

Para Pierre Bourdieu, o habitus remete a um ambiente material de tipo particular, o qual consiste em "sistemas de disposições duráveis, estruturas estruturadas predispostas a operar como estruturas estruturantes" (Bourdieu, 1977, p. 72)1. 0 habitus manifesta-se como um sistema auto-regulador de princípios implícitos e explícitos, globalmente qualificados como princípios geradores, os quais incluem, segundo Bourdieu, dois tipos de relações (cf. Bourdieu ePasseron, 1977, p. 78): (1) a idéia de uma estrutura objetiva que define as condições sociais particulares que produzem as práticas engendradas pelo habitus, e (2) as condições que parecem representar um estado particular do habitus (cf. Cicourel, 1993b, p. 90)².
*Estetexto foi originalmente apresentado no colóquio “Lessystèmes d'enseignements et les catégories nationales de pensée", realizado nos dias 10 a 12 de março de2005 no Château de Coppet, em Genebra, Suíça. Os textos do colóquio foram reunidos no livro L'incons cient académique, Éditions Seismo, 2006.

1. A versão em inglês citada pelo autor é "sys tems of durable, trans posable dispositionsthat are called 'structured structures' or layers". Q uisreproduzir aqui as palavras de Bourdieu (2000, p. 256). 
2. Esta definição, à primeira vista tão desnorteante, acaba se esclarecendo quando se evoca a dimensão "externalista" do conceito dehabitus, tal como utilizado aqui. As duas partes da definição aqui proposta remetem a práticas. $\mathrm{Na}$ primeira parte, 0 autor interroga acerca da noção de "princípios gera dores" denível superior (normas implícitas ou explícitas, valores, regras) que subentenderiam o comportamento dos agentes envolvidos nessas práticas. D e outro lado, a segunda parte insistenas condições locais emergentes associadas a um estado particular do habitus. $\mathrm{Na}$ seqüência deste capítulo, o leitor deve reter essa acepção do termo habitus toda vez que o termo for utilizado (à guisa de precaução, 0 termo está grafado em itálico semprequeutilizado em seu sentido "externalista").

3.0 termo inglêsélifeform, por vezes traduzido pela expressão "mundo vivido". Preferimos aqui a tradução em geral adotada na tradição de Schütz.
A trajetória de vida inicial dos bebês e das crianças pode ser vista como uma espécie de "instituição total" (G offman, 1961) chamada "casa" ou "domicílio". M ais tarde, essa trajetória de vida se encerra, por vezes do mesmo modo, no interior de instituições burocráticas denominadas "retiros de aposentados", "casas de repouso" ou "hospital". A noção de instituição total, encarada na perspectiva de uma criança ou de uma pessoa idosa, significa que tanto a residência como a casa de repouso constituem um ambiente altamente constrangedor. Ele é muitas vezes percebido como uma forma de imposição arbitrária, eventualmente compreensiva, mas não negociável, de uma autoridade sobre o mundo da vida ${ }^{3}$ de um indivíduo. O s recém-nascidos, os bebês, as crianças, os adultos idosos frágeis e os mentalmente debilitados são concebidos como se necessitassem de cuidados constantes; seu comportamento, seu vestuário, sua alimentação, seus medicamentos, tudo é concebido como requerendo um acompanhamento, um controle e uma intervenção constantes.

A concepção da prisão como uma espécie de habitus constitui, entretanto, uma exceção, pois o controle social tendea ser encarado nesse caso como uma punição necessária, a despeito do fato de o intento de reabilitação ser raramente levado a cabo.

Apesar de existir um acordo tácito sobre o que deve ser incluído na categoria das instituições totais, quase sempre faltam dados sistemáticos sobre as condições de vida aí preval ecentes. As condições de vida no interior de um habitus determinado podem decerto diferir, assim como os conhecimentos por vezes limitados que uma dada comunidade detém sobre si se apóiam em fontesficcionais, ou ao menos destinadas ao grande público. Eis por que um dos objetivos deste artigo é identificar certas propriedades gerais que, embora associadas à noção de habitus, não devem ser tomadas como evidentes.

$\mathrm{N}$ o interior de um domicílio ou de um ambienteinstitucional como um orfanato, o estudo do número, do comportamento edos encargosatribuídos aos diversos responsáveis representa sempre um desafio empírico. Q uando sepassa do estudo deum domicílio ao deum ambienteescolar, o conceito de "instituição total" deixa de ser apropriado, e essetermo torna-seainda mais obsoleto quando os indivíduos al cançam níveis superiores de educação, ou então quando, em seguida, a maior parte deles tem acesso ao mercado de trabalho.

A socialização precoceno interior dasfamílias édifícil de estudar. Como um número crescente de pais apela a profissionais para cuidarem de seus 
filhos, por conta de suas obrigações profissionais, a noção de habitus tornase menos nítida em termos conceituais: o controle virtualmente total dos pais é assim delegado a outras pessoas, cujas práticas de socialização são difíceis de identificar de modo sistemático. 0 conceito de habitus parece cada vez mais próximo de um conjunto de atividades vagamente associadas e mescladas que variam entre as culturas, e mesmo no interior de uma mesma cultura, incluindo aí, de maneira sistemática, a idéia de alguma forma de vigilância do comportamento, das práticas al imentares e de higiene. U ma perspectiva intercultural obriga 0 analista e 0 leitor a relativizar 0 que ele considera natural, mas não evita o problema geral suscitado pela noção de "inconsciente acadêmico".

Para adultos idosos, pode-se imaginar que exista uma socialização, meio arrevesada, para a morte; as pessoas idosas tentam preservar sua competência de adultos perante a doença, diante de um cérebro em degenerescência (demência) ou da perda decomportamentosesperados, tanto em termos cognitivos como culturais. A recusa, o humor ou a depressão que afetam sua gradual incapacidadeacabam por setornar uma maneiradeviver, amiúdeacompanhada por suspeitas dos que (como as crianças ou os amigos) Ihes sugerem renunciar a uma parcela desua liberdade, passando a tomar decisõesem lugar delesa respeito dealimentação, finanças, cuidados médicoseatémesmo no tocanteà utilização detransportes públicose privados. As crianças em idadepréescolar eosadultosidosossão cada vez mais confinados no quesepodedesignar como "instituições quase-totais", centros de acolhimento ou habitusnos quais se organizam aalimentação, os exercíciosfísicos, asinteraçõessociais, as simulações cognitivas, as saídas, as atividades musicais e lúdicas. Essas diferentes atividadessão exercidas demodo concomitante. Ascrianças eosadolescentesbuscam adquirir o saber, as capacidades comportamentais e os desempenhos associadosao estatuto deadulto, com a liberdadeeosprivilégiosqueem princípio lhe parecem estar associados.

U ma perspectiva comparativa e intercultural pode, em parte, esclarecer a noção de habitus ao registrar diferenças na maneira como os bebês e as crianças supostamente tendem a adquirir um conhecimento sobre o mundo. Tomemos o exemplo da noção comum segundo a qual alguém que "dispõe detodos os sentidos" pode ser considerado uma pessoa responsável, apta a compreender e a avaliar o pensamento dos demais adultos num ambienteprático. Parece haver a esse respeito concepções populares estruturadas de maneira similar, até mesmo de modo invariante, no âmbito de tradições culturais diversas. 
A antropologia oferece uma ajuda parcial à nossa imaginação, por vezes um tanto limitada por nossa cultura, ao transcender os constrangimentos perceptivos e conceituais ligados ao nosso "inconsciente acadêmico". As pesquisas interculturais servem para nos lembrar quanto à tendência dos universitários a considerar seus conceitos (amiúde ocidentais) como óbvios ea mobilizá-los em suas investigações como se fossem, ao menos num primeiro momento, evidentes. Poderia ser diferente? Em absoluto. M esmo quando inventamos termos como coorte de populações, taxa de fertilidade, anáfora, teoria dos jogos, habitus, superego etc., começamos a nos escorar no senso comum, em intuições sobre o caráter "apropriado" ou não de um termo, antes mesmo de buscar defini-lo de modo diverso, conforme a teoria e a prática próprias a uma disciplina acadêmica. Em outras palavras, quaisquer domínios de erudição e de conhecimento estão enraizados numa visão culturalmenteaceita etácita de um mundo compartilhado queparece evidente.

Tentar colocar em suspenso o caráter evidente do mundo percebido

O universitário ou o escritor de ficção tentam com freqüência "chocar" o leitor ao Ihe apresentar uma perspectiva "estranha" ou exótica do mundo, buscando assim um modo de transcender o cotidiano partilhado que parece evidente. Alfred Schütz $(1945 ; 1962)$ procurava transmitir essa problemática ao fazer referência à idéia de "realidades múltiplas". Suponhamos, por exemplo, que um "estrangeiro" se depare com uma situação da vida cotidiana que não Ihe pareça familiar. Schütz suscita então a seguinte questão: que tipos de mudança de pensamento são necessários para se adaptar a esse novo ambiente? 0 s imigrantes, assim como aqueles cujo comportamento é percebido como "estranho", defrontam-se por vezes com esse problema. 0 estrangeiro de Albert Camus (1946) descreve a maneira pela qual uma pessoa pode ser transformada numa espécie de pária apenas por ser percebida como al guém que exprime condutas singulares ou "instáveis".

U ma expressão típica da língua francesa - tout ce qui va sans dire et qui va de soi ("tudo que está na cara, que parece óbvio") - expressa bem esse fenômeno. Como abordar o que permanece "invisível", incorporado em nossa visão do mundo, e que, por sua natureza original, é percebido como um objeto evidente da prática e do discurso no interior de diferentes campos sociais? N ossa principal hipótese é afirmar que as ciências naturais, e em menor medida as ciências sociais, não foram capazes de escapar a essa 
regra ou diretriz do "inconsciente acadêmico". Por conseguinte, vamos começar nossa recensão com breves referências a práticas culturais diferentes no intuito de colocar em suspenso, pelo menos em parte, nossas próprias concepções não questionadas acerca das atividades cotidianas.

Alfred Schütz $(1954 ; 1962)$ notava que a observação e a interpretação das informações julgadas como "dados" pertinentes a uma teoria estão sempre comprometidas pelo fato de que o analista participa de modo irremediável no curso de ação, mesmo quando utiliza, por exemplo, informações procedentes da demografia, dos recenseamentos ou das pesquisas de opinião. Tais dados "objetivos" requerem categorias pré-selecionadas e trocas de comunicação com os sujeitos da pesquisa com vistas a confirmar a "objetividade" das informações registradas e manipuladas. Schütz observava que

[...] o mundo da natureza, tal como é explorado pelos cientistas, não "significa" nada para as moléculas, os átomos e os elétrons que o compõem. Em compensação, o campo de observação do especialista em ciências sociais, a realidade social, dispõe de uma estrutura de significação e de pertinência para os seres humanos que nela vivem, agem e pensam. Por meio de uma série de artefatos de senso comum, eles pré-selecionaram e préinterpretaram esse mundo, tendendo a experimentá-lo como sendo a realidade de sua vida cotidiana (1954, pp. 266267; cf. 1945; 1953).

Sobre esse problema esboçado por Schütz, o leitor pode se valer do estudo bem útil de Lenoir (2004) a respeito do modo pelo qual a definição das categorias demográficas adotadas pelos ministros franceses influenciou a definição das práticas sociais.

A plataforma temática da rede ESSE ${ }^{4}$ notava que o empreendimento de acumulação de conhecimentos, ao qual a ciência se consagra, somente poderia subsistir com a atividade subjacente de um sistema educativo. Por conseguinte, a educação representa um potente mecanismo institucional para a produção e a transmissão de esquemas cognitivos. Enquanto quasehabitus, a educação transmite e concebe como evidentes certos princípios de organização social. Por exemplo, as divisões específicas, tais como a oposição entre Letras ou H umanidades e as ciências, entre as ciências "duras" e "moles", entre o que é "quantitativo" e "qualitativo" etc., adquirem certa autoridade. A noção de "inconsciente acadêmico" direciona nossa atenção para o fato de que os pesquisadores devem treinar sua habilidade em colo-
4.Ver site www.espace sse.org. 
car em suspenso sua atitude natural perante o mundo comumente apreendido e considerado evidente (cf. Schütz, 1962; Pollner, 1987).

Perspectivas sobre 0 desenvolvimento dos bebês e das crianças

As pesquisas sobre as teorias populares do espírito ressaltam a importância das práticas educativas (mediadas pelas pessoas que tomam conta das crianças, adultos ou jovens) na atribuição e na avaliação da aquisição pela criança de habilidades cognitivas e socioculturais, tais como a utilização da linguagem, a manifestação das emoções, as competências ligadas à resolução de problemas ou ainda as práticas interativas.

Segundo certos psicólogos do desenvolvimento (cf. Gopnik, 1993; Gopnik e M eltzoff, 1997), a perspectiva científica remete à aquisição de uma teoria do espírito, ou seja, à capacidade da criança de reconhecer outrem e atribuir aptidões mentais às pessoas com as quais interage. Certos elementos característicos dessa capaci dade seriam detectáveis desde a idade de três anos. N oções como as de reciprocidade de perspectivas (cf. Schütz) e de assunção de papel (cf. M ead, 1934) são vistas como aptidões essenciais que permitem à criança atribuir perspectivas a outrem. C ertas capacidades cognitivas, como a recorrência, a possibilidade de se colocar no lugar de outrem etc., constituem, aos ol hos de Premack (2004), condições necessárias à resolução de problemas com que se defrontam as crianças.

A literatura psicológica descreve sobretudo pesqui sas levadas a cabo em laboratório sobre as manifestações cognitivas e emocionais dos bebês e das crianças. Todavia, tais manifestações apóiam-se de maneira inevitável em artefatos culturalmente produzidos, bem como em expectativas e regularidades comportamentaise sociais, tanto implícitas como explícitas. Saberese atividades socioculturais são sugeridos, sem que haja nenhuma menção explícita ao habitus (com exceção das pesqui sas deTomasello jámencionadas).

D esdecedo, por volta dos nove meses, o bebê parece revelar certas habilidades motoras, perceptivas e lingüísticas. O s que cuidam dos bebês dispõem inclusive de noções de senso comum para designar tais capacidades. As habilidades ancoradas biologicamente- visuais, auditivas, motoras, verbais ou atékinestésicas - formam-see passam por uma espéciede formatação no interior de ambientes culturais emergentes e por meio de práticas adquiridas progressivamente após o nascimento. Por conseguinte, mecanismos ancorados no cérebro parecem afetar e ser afetados por práticas e artefatos socioculturais (cf. G reenough et al., 1987). Pode-se então dizer que a noção 
de habitus provém de um sistema cerebral que só pode emergir em interação constante com mecanismos e capacidades cognitivas encaixadas em práticas e modelos mentais socioculturais compartilhados.

\section{Exemplos de habitus em bebês e crianças}

O riginário nas ciências cognitivas, o ponto de vista sobre o habitus proposto por Tomasello (1999, p. 79) sugere uma fundamentação empírica desse termo e descreve o conceito como um nicho cultural elementar no interior do qual ocorre o desenvolvimento. Segundo esseautor (cf. I dem, p. 81), já por volta dos nove meses o bebêestá pronto a participar de seu mundo cultural de modo profundamente novo. Por exemplo, a compreensão pela criança de que os outros são agentes intencionais é o que permitiria a ocorrência de uma aprendizagem cultural (imitação), sobretudo ao mimetizar o uso que os adultos fazem dos objetos (utensílios e artefatos). 0 s adultos também podem demonstrar um comportamento de modo explícito e, assim, estimular o interesse e o desejo de emulação por parte da criança.

Tomasello (cf. Idem, p. 10) enxerga no desenvolvimento acelerado das capacidades cognitivas humanas o resultado direto da necessidade que se impõe, tanto às crianças como aos adultos, de sobreviver em diversos ambientes, da melhoria constante de suas capacidades cognitivas ao facilitar a aquisição ea transmissão de conhecimentos, antigosenovos. 0 desenvolvimento cognitivo favorece tipos particulares de aprendizagem cultural, inclusive a criação de quadros de referência comuns, a invenção e a utilização deartefatos, de tradições comportamentais cumulativas e de colaboração na resolução de problemas.

As abordagens cognitivas baseadas em experimentos de laboratório fazem amiúde afirmações apoiadas nas mesmas crenças socioculturais que costumam ser retomadas sem nenhum questionamento pelas pesquisas de campo. Com a intenção de identificar os pressupostos mobilizados pelos experimentalistas, épreciso estudar a maneira pela qual a linguagem descritiva, característica do trabal ho em laboratório, suprime e comprime as reações e as estimativas culturalmente orientadas dos sujeitos que se vêem confrontados às condições experimentais.

O utra maneira de conceber a noção de habitus (também presente em Cicourel, 2004) evoca a discussão feita por K armiloff-Smith (1992, pp. 1521) a respeito das habilidades humanas de representação metacognitivas. Tais saberes são indispensáveis para representar mentalmente (e produzir) 
diferentes formas de organização social. É o caso sobretudo da capacidade de exprimir, verbal ou gestualmente, atividades históricas de representação, metacognitivas, internas ou externas, específicas da espécie humana, tais como os relatos orais ou escritos, ou as "estórias". Assim, as habilidades de representação metacognitivas propiciam aos especialistas das ciências sociais designar o habi tus como um mundo da vida que perdura eno interior do qual os humanos aprendem a utilizar re-descrições de representação como recursos informativos. A capacidade essencial dos adultos e das crianças de re-descrever suas experiências, tanto em termos verbais como por meio de atividades motoras, é portanto algo único dos humanos.

Tomasello (cf. Idem, p. 10) observa que certos processos históricos e ontogenéticos eram exigidos pela adaptação humana, embora as formas particulares de cognição social daí resultantes não fossem determinadas por essas adaptações biológicas especializadas. Logo, a noção de habitus designa, de modo geral, produtos e processos cognitivos e, de outro lado, sua evolução cultural histórica, interdependente e simultânea.

Apoiando-se, entre outros, nos trabalhos de Annette Karmiloff-Smith (1992) e de Lev Vygotsky (1978), Tomasello levanta a hipótese de que existem certas qualidades próprias da espécie que associamos à cognição humana e aos mundos vividos, ou habitus. Por exemplo:

- A capacidade de "identificar" os outros como seres intencionais dotados de estados mentais.

- A aquisição de novas formas de aprendizagem cultural, de desenvolvimento social e de artefatos cognitivos como acumulação de tradições comportamentais modificáveis no curso da história.

- A capacidade das crianças humanas de crescer beneficiando-se do saber (artefatos e tradições) e das habilidades de seu grupo social.

- As experiências de socialização, que incluem a aquisição de representações cognitivas sob a forma de símbolos lingüísticos (bem como de analogias e metáforas elaboradas a partir desses símbolos).

- A capacidade de internalizar certos tipos de interação social, de habilidades discursivas e de indispensáveis mecanismos metacognitivos, tais como as re-descrições de representação.

Esse apanhado sucinto proposto por Tomasello está baseado em primeiro lugar em pesquisas feitas em laboratório com bebês e crianças; ele não lida, pois, com formas interculturais de aprendizagem e de desenvol- 
vimento social. Para seguir o rasto das experiências contemporâneas de socialização, seria preciso um trabalho de campo considerável, capaz de incluir, sem ficar reduzido a tanto, as experiências fundadas em lembranças dos pais ou das pessoas que teriam cuidado das crianças. 0 desenvolvimento humano não foi objeto de observação em períodos temporais prolongados, ao contrário do que fizeram as pesquisas em ecologia comportamental levadas a cabo em biologia com animais não humanos (cf. Krebse D avies, 1993).

A emergência do poder simbólico na infância: algumas provas disponíveis

O smecanismos neurofisiológicos fundamentais, responsáveis pelas contrações específicas dos músculos faciais, estão presentes desde o nascimento (cf. Ekman e Friesen, 1978, e sua utilização do Sistema de Codificação da Ação Facial, ou SCAF). O s recém-nascidos utilizariam o rosto em vez de vocalizações de grande envergadura (exceto para chorar) no intuito de exprimir afetos ou emoções. $N$ as situações da vida cotidiana, os juízos dos adultos sobre os aspectos atinentes ao desenvolvimento das expressõesfaciais e emocionais inscrevem-se no interior de ambientes socioculturais localmente organizados, isto é, naquilo que chamamos um habitus. 0 s adultos avaliam as expressões dos bebês e das crianças para fazer inferências acerca de seu desenvolvimento "normal" ou de seus "atrasos". O sjuízos dos adultos, inclusive os emitidos pelos profissionais da infância, pressupõem que os afetos "culturalmente apropriados", compreendidos de maneira tácita, são essenciais para estimar a adaptação da criança ao habituslocal, inclusive a capacidade da criança de se exprimir e de se afirmar em relação aos que dela se ocupam, bem como diante de outras pessoas. A capacidade da criança de se exprimir e de se afirmar pode ser vista como essencial para exibir o que foi chamado de "poder simbólico".

U ma revisão interessante da literatura proposta por Bloom (2000) observa que as crianças não poderiam aprender a significação das palavras caso não possuíssem certas capacidades mentais não-lingüísticas, a come çar pela capacidade de atribuir a outrem todo tipo de estados mentais a fim de tornar inteligível o mundo externo. D e modo geral, éa "riqueza da vida mental" dos humanos que torna fluida e incessante a aprendizagem das palavras durante a infância. Essa idéia de uma "vida mental rica" só pode emergir nos ambientes físicos e socioculturais que associamos à noção de habitus. 
Um modo mais amplo de caracterizar as noções de habitus e de poder simbólico seria focal izar o discurso das pessoas que cuidam da criança. Bloom (cf. Idem, p. 8) refere-se às pesquisas de Schieffelin (1986, pp. 531-532) sobre "o contexto cultural das crianças que adquirem o Kaluli [...] no interior de um rico ambientelingüístico, cercado deadultos e de crianças maiores que falam umas com as outras, fazendo até mesmo observações a respeito dos próprios bebês [...]". Em seguida, Bloom nota que "osadultos K aluli ensinam explicitamente às crianças a linguagem assertiva (incomodar, humilhar, cobrar), juntando à fórmula lingüística apropriada a pal avra elema um imperativo cujo sentido é 'D iga assim'". 0 ambiente comunicativo no qual a criança é socializada, o habitus, inclui, portanto, tentativas explícitas tendentes a encorajar, pela formulação de frases ad hoc, a aprendizagem de enunciados culturalmente apropriados.

Essas observações de Bloom deixam entrever a maneira pela qual podemos tornar empiricamente válido o conceito de habitus ao estudar as práticas de socialização nacionais e interculturais no âmbito das famílias e das escolas. A descrição de Bloom das pesquisas de Schieffelin sobre as práticas de socialização dos Kaluli também recorre ao conceito de poder simbólico. Por exemplo, a descrição proposta por Schieffelin (1990) das implicâncias, humilhações e cobranças esboça a maneira como as mães K aluli da Papuásia (N ova Guiné) socializam bebês e crianças, por meio de relações de desempenho que refletem diferentes aspectos da noção de poder simbólico. 0 discurso e os movimentos físicos cotidianos são vistos como maneiras de transmitir o sentido do poder simbólico ao ensejo de interações sociais entre crianças pequenas eintegrantes de sua família. Para Schieffelin, as trocas verbais dos Kaluli permitem aos adultos operar como intermediários na transmissão de elementos muito importantes, como os sentimentos, a afeição, a autoridade, a autonomia ea interdependência, uma série de elementos na qual está implicado o poder simbólico.

Schieffelin observa que as mães K aluli se valem de estratégias interativas, como por exemplo afirmar algo ou apelar a alguém, no intuito de criar relações ou vínculos sociais entre irmãos e irmãs, em especial entre as irmãs mais velhas e os irmãos menores. Tais relações exprimem as normas de polidez e de poder que se encontram também nos componentes elementares da vida adulta entre os K aluli, componentes da mesma forma expressos nos cantos, na poesia e nos mitos. U m objetivo cultural importante dos Kaluli é socializar os irmãos mais jovens para que eles possam apelar às irmãs maiores a fim de obter comida, serviços e aten ção. Portanto, a noção 
de "poder simbólico" fica esclarecida quando se observa que os Kaluli parecem exercer um controle vigoroso sobre os outros ao praticarem uma regulação sobre as relações sociais de ajuda e de compartilhamento.

As interações familiares em Buenos Aires e na Cidade do M éxico

Em artigo recente (cf. Cicourel, 2004) dedicado ao conceito de habitus de Bourdieu, apresentei trechos de discurso a partir de um trabalho já publicado (cf. Cicourel, 1978), efetuado no âmbito de uma cultura diferente com o desígnio de esclarecer certos aspectos empíricos das noções de habitus e de poder simbólico. Tratava-se de uma família mono-parental que vivia num subúrbio muito pobre de Buenos Aires e de uma família de classe média que habitava a Cidade do M éxico (para detalhes, ver as referências mencionadas). H avia, é claro, outras famílias na amostra.

Logo surgia uma questão delicada: como o leitor pode avaliar a autenticidade de uma descrição das atividades que o pesquisador atribui à noção de habitus? 0 que deve ser considerado como evidente nesse processo com o intuito de transmitir ao leitor um material "convincente", que foi objeto de uma re-descrição? Aliás, convém ressaltar que todo dado é "re-descritivo", porque somos obrigados a nos socorrer de um vocabulário descritivo comum mesmo quando se efetua a análise de fitas de vídeo ou de áudio.

D eque manera o pesquisador tem acesso ao habitus? T ive a oportunidade de estabelecer uma relação com diversas famílias pobres graças aos esforços dos assistentes sociais encontrados por intermédio de meu amigo Eliseo Veron e deamigos da U niversidade de Buenos Aires. Também entramos em contato com as famílias das classes médias e altas por meio de colegas. As relações com essas famílias foram por vezes duráveis, mas tenho dificuldade em dizer como eu era percebido pelos que estava estudando. A confiança provisória que me era concedida estava baseada na relação que eles mesmos mantinham com os assistentes sociais ou com meus colegas, e ainda pelo fato de que tinham sido prevenidos de que eu era professor numa universidadenorte-americana.

$\mathrm{N}$ a discussão que será objeto de nossa atenção, a dependência da observação e dos materiais discursivos em relação ao quadro empírico real onde foram coligidos constitui ao mesmo tempo uma vantagem e um problema potencial. 0 problema decorre do fato deque talvez se evoque um material discursivo que inclui apenas marginalmente a observação sistemática da situação, antes, durantee após o registro das conversas. $\mathrm{N}$ a pesquisa de campo 
realizada em Buenos Aires ena Cidade do M éxico, eu considerava delicado ficar muito tempo junto dos pais quando falavam com os filhos. Por esse motivo, deixava por vezes um gravador num lugar discreto (mas sempre visível para a pessoa responsável pelas crianças) e esperava nos arredores, enquanto a família interagia. Retomarei adiante esse problema.

Ligar o habitus às práticas. M inhas publicações anteriores descreviam as práticas familiares valendo-se do exemplo da mãe que tentava obter informações junto ao filho (de cinco anos emeio) a respeito de seu dia na escola. Já havia observado interrogatórios desse tipo em inúmeros outros casos e havia presumido serem eles similares à maneira como os pais pertencentes às culturas de perfil ocidental interrogam seus filhos quando retornam do colégio. Em textos anteriores (cf. Cicourel, 1978; 2004), apresentei alguns materiais descritivos que considerava evidentes. Ainda que tenha visitado cada uma das famílias em diversas ocasiões, o volume e a qualidade das observações etnográficas continuavam tênues, pois dispunha de escassas observações sistemáticas detalhadas acerca das atividades cotidianas da família fora de casa. $\mathrm{H}$ avia real izado visitas curtas a cada uma das vizinhanças, estivera na escola das crianças e havia falado com o assistente social em diversas ocasiões. No caso presente, 0 assistente social ajudava as famílias nesse subúrbio proletário pobre de BuenosAires, chamado Avellaneda. U m assistente de pesquisa da Universidade de Buenos Aires visitava todo mês cada família para efetuar o registro de uma interação.

As observações eastrocas discursivas tinham lugar num pequeno apartamento de dois cômodos, domicílio precário no qual a mãe, a filha e o filho dormiam efaziam as refeições. Se existia um pai, elejamais foi visto durante os meses em que o estudo foi realizado. A cozinha e o pequeno banheiro faziam parte de um espaço separado e compartilhado com outras famílias. $\mathrm{H}$ avia água corrente na cozinha. $\mathrm{N}$ os dois quartos, ondea mãe e as crianças passavam a mai or parte do tempo, havia um aquecedor a gás e uma ventilação precária. 0 cheiro de gás era perceptível. Os fatos publicados nesses textos sobre o incidente (cf. Cicourel 1978; 2004) foram relatados após as crianças terem voltado da escola e a mãe do trabalho. A discussão a seguir pretende esclarecer o que antes eu havia considerado evidente (era minha confiançano inconsciente).

O s comentários iniciais da mãe mesclavam certo verniz de polidez amável (decerto devido à presença do gravador) com pedidos à criança que soavam por vezes como ordens. Eu presumia que essa polidez inicial resultava de sua frustração em tentar obter informações junto ao filho 
que pudessem ajudar o pesquisador. De meu ponto de vista, o filho não se mostrava cooperativo e chorava o tempo todo durante o período de gravação. Em termos familiares, poder-se-ia dizer que ele tinha um semblante um tanto "teimoso", mas o monólogo perseverante da mãe poderia levar a crer que a criança era capaz de dar provas de competências comunicativas "normais", e posso confirmar essa capacidade com base nas gravações efetuadas em outras ocasiões.

$N$ esse tipo de pesquisa de campo, o pesquisador se vê quase sempre confrontado com a dificuldade de obter permissão de registrar interações sociais, no intuito de estimar posteriormente a pertinência dos discursos aí proferidos; de fato, muito pouca coisa foi escrita sobre os problemas cotidianos enfrentados por esse tipo de pesquisa, mormente quando os dados se limitam a registros sonoros. Por exemplo, como situar o equipamento de gravação de tal modo que permaneça discreto e não atrapalhe os que estão sendo observados? Assim, mesmo quando as pessoas tentam "gerenciar" aquilo que estão dispostas a revelar ao pesquisador, as tentativas de controlar comportamentos sempre mostram aspectos do que designamos como habitus. Sustento ser impossível para os seres humanos (a não ser talvez num palco) modificar, em períodos de tempo prolongados, suas atividades rotinei ras com a intenção de enganar o observador.

Lembremos que a criança se recusava a falar. Algumas informações sobre o contexto ajudam a esclarecer tal recusa. A parentemente, ela havia visto 0 pesquisador colocar o equipamento (contendo 0 gravador) no alto de um armário grande. A observação desse movimento pode têla assustado porque, graças ao gravador, ouviu-se a mãe dizer à criança (tão logo o pesquisador se ausentou), "isso não vai te fazer nada..." e "será que você tem medo? Isso não vai tefazer nada, nada mesmo". Sea criança de fato se assustou com o equipamento, também a mãe foi incapaz de controlá-la e, portanto, tornou-se impossível para ela criar um ambientefamiliar ideal tendo em vistaa presença do pesqui sador. A criança continuava a chorar, mas suas observações hesitantes sugerem outra razão para o choro persistente que a agitava naquele dia: um colega de turma a havia esmurrado e isso pode ter contribuído para seu comportamento. Em seguida, a irmã confirmou que um colega da escola havia batido no irmão.

0 gravador do pesquisador não desempenhou afinal um papel tão importante como havíamos pensado de início. A criança parecia infeliz na escola e a irmã forneceu detalhes sobre 0 incidente. A mãe, no entanto, demonstrava querer que o filho exibisse competências comunicativas "nor- 
mais", decerto pensando no interesse do pesquisador. N ão obstante, ela revelava um comportamento que costumamos associar à noção de habi tus.

A despeito das intenções da mãe, esse episódio sugereuma prática cultural que ilustra o que pode ser chamado de poder simbólico; a demanda de informações por parteda mãeem relação ao filho estava emoldurada por um pleito insistente eemocional (como vimos no caso dos Kaluli). A troca, por sua vez, poderia também refletir a capacidade do filho de exercer seu poder simbólico: "resistir" aos pleitos e às ordens da mãe. Todavia, da mesma forma era possível que o incidente na escola fosse suficientemente incômodo para que a criança quisesse apenas ser reconfortada pela mãe em lugar delhe relatar o que havia ocorrido naquele dia. D iferentes explicações podem ser aventadas, mas carecemos dos detal hes etnográficos consistentes e convincentes para Ihes dar algum fundamento. Em minha análise inicial, posteriormente retomada, não havia posto em questão, de modo adequado, as circunstâncias ligadas à coleta do material discursivo porque assumira que meus dados eram evidentes.

Contudo, a filha (de oito anos e meio) estava impaciente para dizer à mãe o que acontecera na escola. A irmã parecia agir como mãe substitutiva: passava a maior parte do dia com o irmão. Seu comportamento assemelhava-se às práticas de socialização que relacionamos com a noção de habi tus, as mesmas descritas por Schiefflin no caso dos Kaluli: a irmã cuida sempre do irmão menor, etambém o faz quando a mãe está trabal hando na fábrica.

Q ual a idéia geral subjacente ao reexame das análises desses fragmentos de dados provenientes da pesquisa em Buenos Aires? As fontes documentais abstratas derivadas do conceito de habitus raramente são detal hadas o suficiente para esclarecer os tipos de práticas de socialização que, na mai oria das vezes, são apenas parcialmente observáveis. 0 s materiais discursi vos parecem fornecer indicadores válidos ao pesquisador, os quais Ihe permitem fazer inferências sobre as atividades da vida cotidiana. Todavia, enquanto não pudermos oferecer descrições etnográficas detal hadas e amostragens de comportamentos vinculados a sujeitos variados, em épocas e campos de ati vidade diferentes, devemos considerar evidentes os inúmeros detalhes sobre os quais se apóiam nossas afirmações.

Interação familiar na Cidade do México

N as minhas publicações precedentes (cf. Cicourel 1978; 2004), também apresentei materiais provenientes de uma família de classe média (o 
pai trabalhava como técnico na companhia nacional de telefones). A metodologia era similar, já que eu podia ter acesso a famílias de diferentes níveis socioeconômicos por intermédio de colegas e amigos da U niversidade N acional (Unam), na Cidade do M éxico, instituição na qual eu havia lecionado. U ma doutoranda em psicologia da infância, que se tornara minha assistente de pesquisa, informou que seu pai (um médico) era diretor de um imenso conjunto de moradias populares na região sul da Cidade do M éxico, não muito longe da U niversidade. Foi elequem facilitou o contato com essas famílias, selecionadas por acaso, em função do aluguel pago por cada uma delas.

Além de passar al gum tempo com cada uma dasfamílias nos apartamentos, também observei e fiz gravações na creche e no jardim-de-infância do conjunto. Em várias famílias de baixa renda, os dois pais trabal havam etinham a possi bilidade de deixar seus filhos de al guns meses sob a guarda da creche. 0 s bebês e as crianças entravam na creche ou no jardim-de-infância pela manhã eeram apanhadosno final da tarde. D urantea semana, algumas crianças passavam mais tempo com os educadores do condomínio do que com os pais.

A família aqui estudada vivia num apartamento "confortável" e empregava uma mulher indígena proveniente do sul do país. As trocas (que não serão tratadas aqui em detalhes) ilustram outra tentativa da mãe de manter um diálogo "normal" com o filho em benefício do pesquisador. N ossa atenção centrar-seá aqui na mãe e no filho de quatro anos. U ma irmã menor também estava presente (de dez meses), além de um irmão mais velho (de dez anos).

O s episódios gravados refletem mais uma vez as atividades que costumamos associar à noção de habitus. No caso da família aqui descrita, formulamos a hipótese de que o filho de quatro anos era capaz de exercer (como no caso da criança de Buenos Aires) uma forma de poder simbólico: ele não aceitava a definição maternal da situação, a saber, sua insistência para que comesse 0 almoço.

$\mathrm{N}$ um primeiro momento, a mãe falava com voz macia e controlada, enquanto acomodava o filho à mesa, dizendo-Ihe "você vai comer" efrisando que ela mesma ia servi-lo. D epois de a criança ter reiteradamente se recusado a comer, parecia se produzi r uma mudança imediata na entonação de voz da mãe. $\mathrm{N}$ a medida em que o diálogo se desenvolvia, aumentava a sensação de que a voz da mãe se tornava mais forte e irritada enquanto nomeava os al imentos que desejava que o filho comesse. 0 filho recusava- 
se a cooperar ("não, não quero comer arroz"). D epois, com uma voz queme parecia vibrante de raiva, ela forçou: "Então, o que você quer?". A resposta da criança assemelhava-se a um "não" queixoso. Lembrem-se que antes (cf. Cicourel, 1978; 2004) eu não havia atribuído um caráter problemático às reações da mãe em minha avaliação: pensava então naquelas entonações da voz maternal como evidentes.

A mãe perguntou em seguida se o filho queria a mamadeira, eno ato deixou bem claro queelenão deveriatomá-la. 0 filho pediu então quelhetrouxesse a mamadeira. Tudo leva a crer que a natureza conflitiva da troca persistiu. A mãemencionou ao filho mais velho a presença do gravador elhedisse que estavam sendo gravados. Ela parecia incapaz de manter a aparência de um habi tus"normal" diantedasnecessidades da pesquisa edeimpor ao filho sua autoridade. A recusa persistente da criança de comer e parar de chorar pareceu irritar a mãe, o que me soou como al go próximo à noção de poder simbólico. Será que o comportamento do filho aborrecia a mãe por conta da presença do gravador ou porqueel esecomportava de um modo quea irritava (ou a incomodava?), ou as duas coisas? Tenho a sensação de que todas essas condições estavam presentes.

Essebrevefragmento procedente do contato com uma família naCidade do M éxico revela outra vez certos elementos característicos das práticas culturais da vida cotidiana, os mesmos que associamos às condições de social ização normais eque podem estar ligadas ao conceito de habitus. N uma conversa com a mãe logo após a sessão referida acima, el a confirmou queo filho menor semprecriava problemas, porque queria comer apenas aquilo de que gostava. Elatambém afirmou queestava contrariada (eaparentementeincomodada) porque o filho ainda bebia mamadeiras de leite aos quatro anos.

Como mencionei antes, em algumas ocasiões pude observar com atenção o encadeamento da vida cotidiana no interior da família, fazendo uma amostragem sistemática em diferentes horas, dias e semanas. Por conta do número de famílias envolvidas na pesquisa, fui obrigado de fato a me restringir a um programa menos sistemático; contentei-me com apenas um dia, no qual meu emprego do tempo permitia deixar o gravador funcionando por cerca de duas horas. M inha assistente de pesquisa, contudo, estava em condições de visitar todas as famílias a cada mês, 0 ano inteiro, e registrar as interações de seus membros sempre que eu me ausentava da Cidade do M éxico.

As limitações relacionadas aos aspectos etnográficos da pesquisa devem ficar claras para o leitor. Ainda que eu pudesse morar perto do condomínio, 
teria sido difícil empreender o estudo como se o lugar fosse um pequeno povoado independente. A organização estrutural do condomínio (grandes prédios com inúmeros apartamentos), da creche, do jardim-deinfância, das escolas, das áreas de lazer, dos estacionamentos e das pequenas lojas, era tão dispersa que eu não teria logrado observar com facilidade o cotidiano das famílias selecionadas. Essa ausência de um contexto de povoado era em parte compensada pela possibilidade de acesso a um espectro mais diversificado de situações e práticas associadas à noção de habitus. As referências à noção de habitus presentes na literatura não tratam da maneira pela qual se poderia captar ao mesmo tempo as diferenças ligadas à estrutura social e aquelas vinculadas ao pertencimento cultural.

O s trechos de discurso aqui apresentados não dão conta dos esforços indispensáveis e trabal hosos envolvidos no estudo das condições que associamos às noções de habitus e de poder simbólico. Refiro-me sobretudo às dificuldades decorrentes da necessidade de obter permissões para visitar, observar e gravar interações familiares cotidianas, aqui associadas às noções dehabituse poder simbólico. N ão obstante, os fragmentos discursivos apresentados deveriam fornecer aos leitores alguns detal hes sobre as práticas culturais que não estão contidas na noção sugestiva de "nicho cultural" proposta por Tomasello.

\section{A noção de habitus como instituição quase-total e a ecologia dos mundos da vida frouxamente associados a eles}

Ao longo da discussão precedente, mencionei a noção de "instituição total" como algo evidente. $\mathrm{N}$ em a noção de habitusnem a de instituição total possuem características estruturais e morfológicas evidentes. 0 que parece claro, ao menos num primeiro momento, na discussão da instituição total proposta por G offman (1961), éo aparente controle total epermanentesobreavida dosindivíduos, quechegaa ponto deincluir a capacidadedeingerir alimentose eliminar os detritos corporais. N o caso das crianças, o monitoramento detais atividades deve forçosamenteser efetuado por razões de sobre vivência. No entanto, faltam-nos dadosempíricos sistemáticos sobreas dife rentes maneiras pelas quais os pais, ou aqueles que os substituem, exercem esse controle da prole (cf. W hiting, 1963, para exemplos não ocidentais).

Com o desenvolvimento de sua independência, a capacidade da criança de comer sozinha ocorre antes da capacidade de eliminar os detritos corporais ou de se vestir de modo correto. As diferenças interculturais ajudam a 
esclarecer o problema, embora não eliminem a evidência de que se revestem tais práticas para o pesquisador, imerso em sua própria perspectiva cultural que, por suavez, éenglobada no nicho acadêmico no qual seinserea pesquisa. N os países ocidentais, poucas tentativas de esclarecer a noção de habitus são capazes de citar e de integrar as inúmeras contribuições (que ora coincidem, ora se contradizem), provenientes de uma grande variedade de domínios (biologia do desenvolvimento, pediatria, pedopsiquiatria, neurociências, neurologia, psicologia do desenvolvimento, psicologia clínica, lingüística, assistência social, logopedia, antropologias, sociologias, nutrição, educação da tenra infância etc.).

A integração da cognição eda cultura énecessária sequisermos esclarecer noções como as de habitus e poder simbólico. No correr deste artigo, sugeri que essas noções estruturais úteis deveriam estar ligadas a atividades que possam ser observadas egravadas pelospesquisadores. É por meio do conhecimento detal hado dessas atividades, estudadas em seu ambiente natural, que podemos avançar hipóteses sobre a socialização das crianças e reunir elementos de prova quanto às hipóteses que colocam em jogo tais conceitos. Cumpre, portanto, distinguir entre: (1) os quadros de referência metodológicoseteóricos (tanto os de senso comum como oscientíficos) existentes no momento em que fazemos observações diretas e criamos re-descrições de representação que chamamos "dados"; e (2) as re-descrições de representação utilizadas na análise dos "dados" que ligam as provas à teoria quando descobertas substantivas são reivindicadas.

Este artigo sugeriu, em bases exploratórias, al gumas maneiras de questionar conceitos edados quetendemos a considerar como evidentes porque quase sem pre comunicamos nossas reflexões acadêmicas a colegas por meio de conferências e textos que assumem como algo evidente os termos da academic life as usual ("a vida acadêmica de sempre").

Referências Bibliográficas

B Lo o M , P. (2000), H ow children learn the meaning of words. C ambridge, M assachusetts, MIT Press.

Blum ER, H . (1969), Symbolic interactionism, perspectiveand method. Englewood Cliffs, Nova Jersey, Prentice-H all.

Bourdieu, P. (1977), 0 utlineof a theory of practice. C ambridge, C ambridgeU niversity Press. . (2000), Esquisse d'une théorie de la pratique. Paris, Seuil. 
Bourdieu, P. \& Passeron, J.-C. (1977), Reproduction in education, society and culture. Londres, Sage.

Camus, A. (1946), The stranger. N ova York, Vintage Books.

Cicourel, A. V. (1978), "Interpretation and summarization: issues in the child's acquisition of social structure". In: Glick, J. \& Clarke-Stewart, K. A. (eds.), The development of social understanding. N ova York, G ardner Press, pp. 251-281. . (1993a), "H abitusaspekte im entwicklungs und erwachsenenalter". In: Gebauer, G. \& Wulf, C. (eds.), Praxis und ästhetik: neue perspektiven im denken von Pierre Bourdieu. Frankfurt, Suhrkamp, pp. 148-173.

. (1993b), "Aspects of structural and processual theories of knowledge". In: Calmoun, C., LiPuma, E. \& Pontone, M. (eds.), Bourdieu: critical perspectives. Cambridge, Polity Press, pp. 89-115.

. (2004), "L'habitus et le pouvoir symbolique comme processus sociocognitifs: quelques suggestions empiriques". In: Bouveresse, J. \& Roche, D. (eds.), La liberté par la connaissance: Pierre Bourdieu (1930-2002). Paris, O dile Jacob, pp. 163-188.

Ekman, P. \& Friesen, W. V. (1978), U nmasking the face. Englewood Cliffs, N ova Jersey, Prentice-H all.

Goffman, E. (1961), Asylums essays on the social situation of mental patients and other inmates. Garden City, N ova York, Anchor Books.

GopNICK, A. (1993), "H ow we know our minds: theillusion of first-person knowledge about intentionality". Behavioral and Brain Sciences, 16: 1-14.

Gopnick, A. \& Meltzoff, A. (1997), Words, thoughts and theories. Cambridge, $M$ assachusetts, M IT Press.

Green ough, W. T., Black, J. E. \& W allace, C. S. (1987), “Experience and brain development". Child D evelopment, 58 (3): 539-559.

Karmilo fF-SM ITH , A. (1992), Beyond modularity: a devel opmental perspectiveon cognitive science. Cambridge, M assachusetts, M IT Press.

Krebs, J. R. \& D Avies, N . B. (1993), An introduction to behavioural ecology. Oxford, Blackwell.

LenolR, R. (2004), Généalogie de la morale familiale. Paris, Seuil.

M ANDLER, J. M . (2004), The foundations of mind: origins of conceptual thought. N ova York, Oxford University Press.

M ead, G. H. (1934), M ind, self and society. C hicago, University of C hicago Press.

PolLner, M . (1987), M undane reason: reality in everyday and sociological discourse. N ova York, Cambridge University Press.

Premack, D. (2004), "Is language the key to human intelligence?". Science, 303 (5656): 318-320. 
Texto recebido em 5/ 3/2007 eaprovado em 5/3/2007.

Aaron V. Cicourel é professor de ciência cognitiva, de pediatria e de sociologia, tendo trabalhado na U niversidade da Califórnia, em San Diego, e hoje lecionando e pesquisando na U niversidade de Berkeley (Califórnia). Autor de obras inovadoras, entre as quais $M$ ethod and measurement in sociology (N ovaYork, FreePress, 1964), Thesocial organization of Juvenile justice(N ova York, W iley, 1968; Londres, $\mathrm{H}$ einemann, 1976; N ew Brunswick, N .J., Transaction Books, 1994), Cognitivesociology: language and meaning in social interaction (Londres, Penguin, 1973; N ova York, Free Press, 1974). E-mail: cicourel @cogsci.ucsd.edu.
Schieffelin, B. (1986), "The acquisition of Kaluli". In: Slobin, D. (ed.), The crosslinguistic study of language acquistion. H illsdale, N ova Jersey, Erlbaum, pp. 525593.

. (1990), The give and take of everyday life: language socialization among the Kaluli. N ova York, Cambridge University Press.

Sснütz, A. (1945), "On multiple realities". Philosophy and Phenomenological Re search, 5: 533-575. (1953), "Common-sense and scientific interpretation of human action".

Philosophy and Phenomenological Research, 14: 1-38. . (1954), "Concept and theory formation in the social sciences". Journal of Philosophy, 51 (9): 257-273. . (1962), Collected papers I. The problem of social reality. D ordrecht, Kluwer Academic Publishers.

Tomasello, M. (1999), The cultural origins of human cognition. Cambridge, M assachusetts, $\mathrm{H}$ arvard University Press.

VYGOTSKY, L. (1978), M ind in society: the development of higher psychological processes. Cambridge, M assachusetts, $\mathrm{H}$ arvard University Press.

W EBER, M . (1968), Economy and society: an outline of interpretive sociology. 3 vols. N ova York, Bedminster Press.

W Hiting, B. (ed.). (1963), Six cultures, studies of child rearing. N ova York, Wiley.

\section{Resumo}

As manifestações institucionais e cotidianas do habitus

0 texto examina o conceito de habitus como processos de aquisição de capacidades por bebês e crianças, em meio às práticas e experiências cotidianas de socialização em ambientes de interação familiar, valendo-se de investigações empíricas empreendidas na Cidade do M éxico e em Buenos Aires.

Palavras-chave: Habitus, Instituiç̃es; Socialização; Poder simbólico; Cultura; Interação familiar.

\section{Abstract}

Institutional and everyday manifestations of habitus

The article explores the concept of habitus viewed as a process through which babies and children acquire capacities in their daily practices and experiences of socialization within contexts of family interaction, based on data from surveys conducted in $M$ exico City and Buenos Aires.

Keywords: Habitus; Institutions; Socialization; Symbolic power; Culture; Family interaction. 